\section{Direct sensing of total alkalinity profile in a stratified lake}

\section{Ghahraman Afshar ${ }^{1}$, M.-L. Tercier-Waeber ${ }^{1}$}

\section{B. Wehrli2,3, E. Bakker ${ }^{1 *}$}

OPEn 2 Access

\section{Abstract}

We demonstrate the direct detection of a total alkalinity depth profile through the use of an integrated thin layer electrochemical modulation instrument which acts as an alkalinity sensor. The technique uses a chemically selective proton pump that alters the concentration of hydrogen ions in the thin layer sample. As the proton pump releases hydrogen ions the resulting $\mathrm{pH}$ is recorded at the $\mathrm{pH}$ probe placed directly opposite the thin sample gap. This results in an acid-base titration that takes place directly in the thin layer sample and therefore obviates the need for traditional sample manipulation. Collected samples from a stratified lake were assessed with this alkalinity probe to record a total alkalinity profile, indicating a substantial increase from 2.59 to $4.11 \mathrm{mM}$ with depth. Results of the new method were in excellent agreement with titration alkalinity data, and offer the potential for autonomous on site measurements of this key parameter.

Received 6 June 2016 | Accepted 17 October 2016 | Published 10 November 2016

\section{Introduction}

Calcium carbonate precipitation in hard water lakes is triggered by blooms of algae and cyanobacteria (Dittrich et al., 2004). The heterotrophic conditions in the deep water (Gruber et al., 2000), and at the sediment-water interface, lead to the accumulation of dissolved $\mathrm{CO}_{2}$ and a decrease in $\mathrm{pH}$ accompanied by partial carbonate dissolution (Ramisch et al., 1999; Müller et al., 2003). As a consequence, the concentration gradients of $\mathrm{Ca}^{2+}$ and $\mathrm{HCO}_{3}{ }^{-}$with depth are often increasing and thereby strengthen the stratification of the water column in summer (Gruber

1. Department of Inorganic and Analytical Chemistry, University of Geneva, Quai Ernest-Ansermet 30, CH-1211 Geneva, Switzerland

Corresponding author (email: eric.bakker@unige.ch)

2. Department of Surface Waters Research and Management, Eawag-Swiss Federal Institute of Aquatic Science and Technology, Seestrasse 79, CH-6047 Kastanienbaum, Switzerland

Institute of Biogeochemistry and Pollutant Dynamics, ETH Zürich, Universitätsstrasse 16, CH-8092 Zürich, Switzerland

et al., 2000). In anoxic systems, sulphate reduction in the sediments and the release of reduced substances like $\mathrm{NH}_{4}^{+}$further contribute to an increase of alkalinity with depth (Pasche et al., 2009). Precise profiling of alkalinity (Stumm and Morgan, 1996) in stratified waters is therefore essential to quantify the dynamics of the carbon cycle, to constrain the pathways of organic carbon mineralisation, and to understand the burial of carbonates in the sedimentary record (Schrag et al., 2013). Typically, alkalinity profiles are obtained from sub-sampling Niskin bottles followed by titration in the laboratory. This approach is cumbersome and offers only limited resolution in space and time and requires additional precautions for anoxic deep-waters where alkalinity changes can occur due to rapid oxidation of reduced components.

Today, techniques have become available to generate the titrant electrochemically and thus provide the possibility of titrations in volumes of a few microlitres without the need for traditional sample manipulation. Early examples include the electrogeneration of hydroxide at an antimony/antimony oxide electrode (Karlmark et al., 1982), while recent efforts used the direct electrochemical transformation of water to produce strong acid or base (van der Schoot et al., 2005). Once integrated into microfluidic devices, these reagent generation principles were combined with a $\mathrm{pH}$ probe to realise a so-called flash titrator. Side reactions involving other electroactive species may lower the coulometric conversion efficiency of direct water electrolysis, rendering its use in complex samples problematic.

Autonomous in situ detection of alkalinity in seawater samples has been demonstrated by Spaulding's group, based on bulk titration and indicator colour change (Spaulding et al., 2014). Classical acid-base titration was also applied for alkalinity detection by Li's group, where the indicator colour change was monitored spectroscopically to predict the endpoint ( $\mathrm{Li}$ et al., 2013). In these reports, traditional volumetry was applied that requires reagents (indicator, acid and base) and complex instrumentation such as pumps, injection valves, and optical detectors.

An alternative approach less prone to interferences involves the electrochemically driven transport of ions across ion-selective membranes (Nagy et al. 1977; Bhakthavatsalam et al., 2006; Ghahraman Afshar et al., 2014, 2015ab). They can be used for the direct detection of total alkalinity by applying a constant current across the membrane and measuring the time required for localised depletion of base to occur. This chronopotentiometric technique is limited by an influence of the diffusion coefficient of the base of interest on the signal (as does the flash titrator mentioned above) and so far exhibits a limited measuring range not suitable for environmental analysis (Crespo et al., 2012; Ghahraman Afshar et al., 2014).

Recently, our group used a selective proton pump membrane to inject hydrogen ions into a thin layer sample while measuring the resulting $\mathrm{pH}$ with a $\mathrm{pH}$ probe placed directly opposite to the proton pump (Ghahraman Afshar et al., 2015a), thereby realising a direct alkalinity sensor. The thin sample layer 
(ca. $100 \mu \mathrm{m}$ ) ensures that the injected hydrogen ions are equilibrated after a short time ( $\sim 2 \mathrm{~min})$, thereby giving a sensor response directly analogous to a volumetric titration. This methodology was assessed here for the direct on site measurement of an alkalinity depth profile in Lake Greifen (Switzerland).

\section{Experimental Section}

Reagents, materials and equipment. Potassium tetrakis[3,5bis(trifluoromethyl)phenyl]borate (KTFPB), tetrakis(4-chlorophenyl)borate tetradodecylammonium salt (ETH 500), chromoionophore I, 2-nitrophenyloctylether (o-NPOE), tris(hydroxymethyl)aminomethane (Tris), acetic acid, sodium acetate, sodium chloride, sodium hydroxide $(1 \mathrm{M})$, hydrochloridric acid $(1 \mathrm{M})$, high molecular weight poly(vinyl chloride) (PVC) and tetrahydrofuran (THF) were purchased from Sigma-Aldrich (analytical grade). Porous polypropylene (PP) membranes (Celgard, $0.237 \mathrm{~cm}^{2}$ surface area, $25 \mu \mathrm{m}$ thickness) were kindly provided by Membrana in Wuppertal, Germany.

Electrochemical equipment. A double-junction Ag/AgCl/3 M KCl/1 M $\mathrm{LiOAc}$ reference electrode was used in potentiometric and voltammetric measurements (6.0726.100 model, Metrohm, Switzerland). Electrode bodies (Oesch Sensor Technology, Sargans, Switzerland) were used to mount both the Celgard and PVC polymeric membranes. A platinum-working rod $\left(3.2 \mathrm{~cm}^{2}\right.$ surface area) was used as a counter electrode. Potentiometric measurements were performed using a high impedance input 16-channel EMF monitor (Lawson Laboratories, Inc., Malvern, PA). Voltammetric measurements were carried out with an Autolab PGSTAT101. Portable $\mathrm{pH}$ meter model $826 \mathrm{pH}$ was applied for $\mathrm{pH}$ detection (Metrohm AG, Switzerland). A commercial submersible multiparameter CTD probe OCEAN SEVEN 305Plus (Idronaut, Brugherio, Italy) equipped with $\mathrm{pH}$ electrode (a combination of $\mathrm{pH}$ and reference electrodes in contact with electrolyte solution behind a gas permeable membrane) and appropriate software provided by the manufacturer (ITERM, REDAS) was used for in situ $\mathrm{pH}$ profiling. All the calibration solutions were prepared in $10 \mathrm{mM}$ of $\mathrm{NaCl}$ as background electrolyte.

Membrane preparation. Proton pump membranes were fashioned from porous polypropylene (PP) membranes (Celgard, $0.237 \mathrm{~cm}^{2}$ surface area, $25 \mu \mathrm{m}$ thickness) as supporting material. The membranes were washed with THF for 2-3 min to remove contaminants. An excess volume of $4 \mu \mathrm{L}$ of the THF-free cocktail solution was deposited on the membrane when it was found to be completely dry (see cocktail preparation below). The impregnation of the cocktail was found to be instantaneous. The pore filling solution composition was assumed to remain identical to the initial THF-free cocktail. The membrane was conditioned in 0.01 $\mathrm{M} \mathrm{HCl}$ for $40 \mathrm{~min}$ and mounted in the electrode body. The inner compartment was filled with $0.01 \mathrm{M} \mathrm{HCl}$. The chemical composition of the proton pump membrane was $120 \mathrm{mmol} \mathrm{kg}^{-1}$ of Chromoionophore I (mmol per kg of cocktail), $60 \mathrm{mmol}$ $\mathrm{kg}^{-1}$ of KTFPB, $90 \mathrm{mmol} \mathrm{kg}{ }^{-1}$ of ETH 500, $150 \mathrm{mg}$ of o-NPOE, total mass of 200 $\mathrm{mg}$ and $1 \mathrm{~mL}$ of THF. The THF was only used to solubilise the solid compounds into the plasticiser and was removed by evaporation before membrane casting membranes. The potentiometric $\mathrm{pH}$ probe membrane was based on a solvent cast PVC membrane, composed of $15 \mathrm{mmol} \mathrm{kg}{ }^{-1}$ of Chromoionophore I, $5 \mathrm{mmol} \mathrm{kg}{ }^{-1}$ of KTFPB, $135 \mathrm{mg}$ of o-NPOE and $62 \mathrm{mg}$ PVC, total mass of $200 \mathrm{mg}$, which was dissolved in $2 \mathrm{~mL}$ of THF and poured into a glass ring (10 mm ID) affixed onto a glass slide. The solution was allowed to evaporate overnight, giving membranes of ca. $0.15 \mathrm{~mm}$ thickness. This parent membrane was cut with a hole-puncher into disks of $8 \mathrm{~mm}$ diameter and mounted into Ostec electrode bodies. The inner compartment consisted of $0.01 \mathrm{M} \mathrm{HCl}$.

Electrochemical cell setup. The cell consisted of a five electrode system in an acrylic container: a proton pump, a $\mathrm{pH}$ indicator electrode, a counter and two reference electrodes. A two-electrode arrangement (see Fig. S-1) with the reference and counter electrodes immersed in the outer contacting solution was used. The distance between indicator electrode and proton pump was defined by a $100 \mu \mathrm{m}$ thick piece of paper tightly placed between them that was removed before filling the vessel with sample.

Electrochemical protocol. Coulometric pulses were applied at the proton pump while the potentiometric readout was recorded at the $\mathrm{pH}$ sensor. An automated method (NOVA, Autolab) consisted of i) open circuit potential determinations for $5 \mathrm{~s}$ at a sampling rate of $10 \mathrm{~Hz}$ (no current flow), ii) anodic potential pulses of varying duration (from $30 \mathrm{~s}$ to $210 \mathrm{~s}$ ) at $500 \mathrm{~Hz}$. Immediately afterwards, the $\mathrm{pH}$ was recorded potentiometrically at the $\mathrm{pH}$ probe.

The proton pump is an ion-selective electrode based on a hydrogen ionselective membrane made from doped porous polypropylene instead of PVC owing to its faster mass transport properties (Malon et al., 2007). An inner solution of $0.01 \mathrm{M} \mathrm{HCl}$ was used as a high concentration of acid is required to release hydrogen ions. The released proton concentration in the thin layer sample was calculated from the total released charge (current integration) and the thin layer volume. A volume of $40 \mu \mathrm{L}$ is typically predicted for the thin layer sample, the value of which is determined by calibration using Faraday's law.

Sample collection and in situ $p H$ measurement. The samples from different depths were collected using a Niskin Water Sampler (Model 1010: General Oceanic, Miami, USA) and stored in polyethylene containers, used here because transition metals were assessed in the same field study. The containers were completely filled to minimise loss of $\mathrm{CO}_{2}$ and the containers were kept closed until measurement. All measurements were performed within a few hours after sampling. One lake-water profile consisted of seven depths: 1, 2.5, 4, 5.5, 7, 8.5 and $12.5 \mathrm{~m}$. pH was detected in situ using an OCEAN SEVEN 305Plus multiparameter CTD probe. The calibration of the $\mathrm{pH}$ sensor was performed as requested by the manufacturer using one-point calibration $(\mathrm{pH} 7$, non-stirring conditions). 
Theoretical fit. Equilibrium theory was used to fit the titration curve of the lake water samples by considering carbonate and bicarbonate as major alkaline species using $\mathrm{pKa}_{1}$ of 6.30 for bicarbonate, $\mathrm{pKa}_{2}$ of 10.32 for carbonate and the initial $\mathrm{pH}$ value obtained by the in situ sensor.

\section{Results and Discussion}

Alkalinity depth profiles were investigated by the thin layer coulometric approach described recently (Ghahraman Afshar et al., 2015a), marking the first time that this technique is applied for an environmental application. The electrochemical cell consisted of a membrane-based proton pump and $\mathrm{pH}$ probe (see Fig. S-2 for potentiometric response of the latter) separated by a thin layer sample (see Fig. 1 for scheme). The lower detection limit (DL) of the methodology is about $0.1 \mathrm{mM}$, obtained by monitoring the minimum detectable $\mathrm{pH}$ change in the absence of buffer The upper DL is found to be at least $100 \mathrm{mM}$, predicted by the titration of the highest possible concentration of strong base (sodium hydroxide) solution. This makes the methodology applicable to environmental systems including highly buffered carbonate lakes (Müller et al., 2016). The thin sample layer remained in physical contact with the bulk lake sample at all times $(100 \mathrm{~mL})$ and was therefore allowed to re-equilibrate after each perturbation step by convective stirring of the bulk

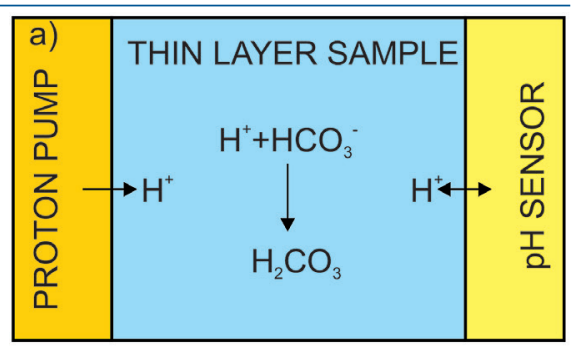

Figure 1 (a) Schematic illustration of th alkalinity probe. (b) Electrochemical cell composed of a proton pump and a $\mathrm{pH}$ probe placed directly opposite. The two reference electrodes (RE1 and RE2) and counter electrode (CE) are inserted in the bulk sample solution. The carbonate species are titrated with the hydrogen ions released from the proton pump. The resulting change of pH is subsequently assesse potentiometrically at the $\mathrm{pH}$ probe. sample. Alkalinity in the unfiltered lake water samples from depths of 1 to $12.5 \mathrm{~m}$ were determined from the inflection point of the titration curves using the thin layer electrochemical instrument (Figs. 2a, S-9b to S-15b). pH was monitored at the $\mathrm{pH}$ indicator electrode as a function of charge, and hence of the released proton concentration, at the proton pump for 11 consecutive excitation pulses of $300 \mathrm{mV}$ (vs. OCP) of 10 to $110 \mathrm{~s}$ duration with $10 \mathrm{~s}$ increment (see Fig. S-3)

The potentiometric response of the $\mathrm{pH}$ electrode after each imposed pulse allowed the determination of the time required to reach equilibration of $\mathrm{pH}$ between the two opposite electrodes and re-equilibration of the thin layer with the natural sample. These values are similar to those determined previously from thin-layer electrochemical titrations in synthetic solutions (Ghahraman Afshar et al., 2015a), suggesting the absence of matrix effects and/or fouling problems. This hypothesis was supported by the comparative alkalinity levels for the same samples obtained from traditional volumetry (reference method ISO 9963:1994, volumetric acid-base titration), which is in quantitative agreement with the values obtained with the alkalinity sensor. Figure $2 \mathrm{~b}$ shows the correlation between the proposed and reference methods: solid line indicates ideality with unity slope and zero intercept. The two methods are in excellent agreement as the least squares fit gives a slope of almost unity and an intercept close to zero $(y=1.018 x-0.062$, $r^{2}=0.997$ ), giving an average relative error of $1 \%$ (see Fig. S-4)
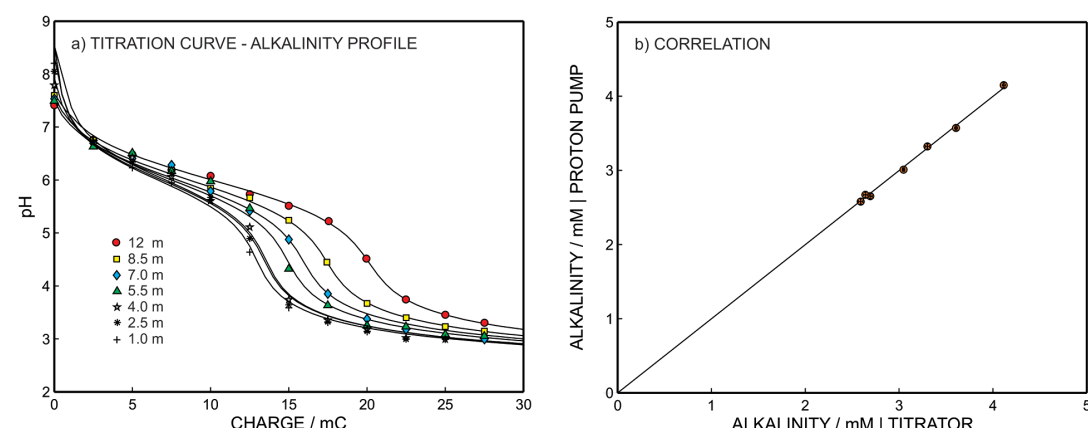

Figure 2 (a) The titration curve for various depths in the range of 1 to $12.5 \mathrm{~m}$ using the thin layer instrument. Solid line is theoretical. (b) Correlation between the thin layer chemical modulation method and volumetric acid-base titration reference method (ISO 9963-1:1994). Solid line shows ideality with unity slope and zero intercept.

The long-term stability of the $\mathrm{pH}$ sensor and proton pump were investigated, and a drift of $0.5 \mathrm{mV} / \mathrm{h}$ was obtained (Fig. S-5). The reproducibility of the proton pump was examined by applying repeated potential pulses of 300 $\mathrm{mV}$ for $30 \mathrm{~s}$, finding an RSD of less than $1 \%(n=5)$, indicating a reproducible release system (Fig. S-6). The influence of temperature on the released charge was examined within the range of 20 to $30^{\circ} \mathrm{C}$. According to Figure S-7, the variation was negligible (RSD $\leq 2 \%$ ). Various sodium chloride concentrations between 
$10^{-5}$ to $0.1 \mathrm{M}$ were examined as background (Fig. S-8), and the released charge was found to increase with higher background concentration. However, this should not affect the precision and accuracy of the technique as it is performed by stopping the potential pulse after reaching a predetermined charge value.

Figure $3 \mathrm{~b}$ shows the alkalinity depth profiles together with the corresponding $\mathrm{pH}$ values (Fig. 3a) obtained in situ from the multiparameter CTD probe at the same depth. An alkalinity level in the range of $4 \mathrm{mM}$ was observed below the bioactive surface layer, in agreement with earlier work (Müller et al., 2016). As observed in Figure 3b, alkalinity increases with depth while Figure 3a shows that this is accompanied by decreasing $\mathrm{pH}$.

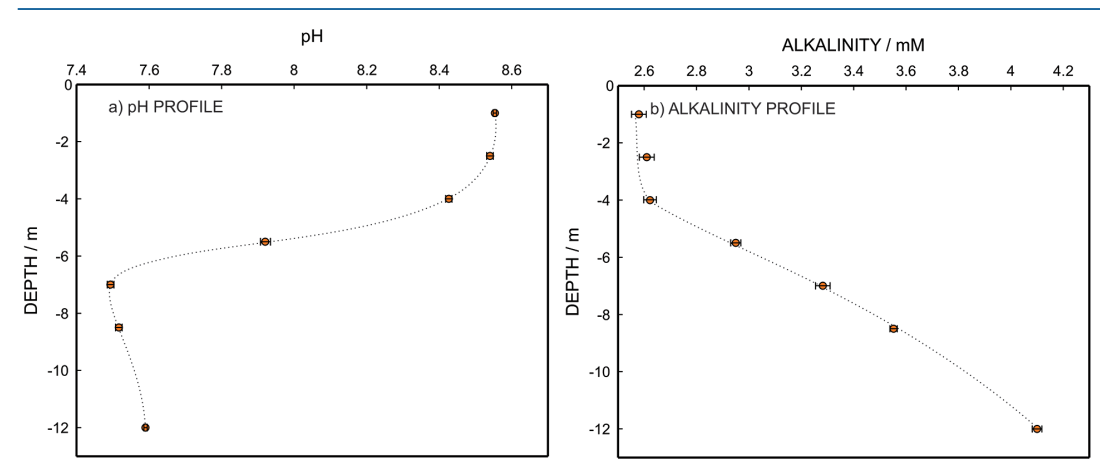

Figure 3 (a) Total alkalinity depth profile and (b) $\mathrm{pH}$ depth profile obtaining during field monitoring on the Lake Greifen (31 August 2015).

In surface waters and during the day, algae and other photosynthetic microorganisms consume $\mathrm{CO}_{2}$ by photosynthesis, which results in an increase of $\mathrm{pH}$. In hard water systems, this promotes the precipitation of $\mathrm{CaCO}_{3}$ onto microorganisms and other microenvironments, which is eventually transported to greater depths by sedimentation, thereby reducing alkalinity at the surface (Gruber et al., 2000). On the other hand, the sediments of hard water lakes act as a source of alkalinity due to anaerobic mineralisation processes and partial calcite dissolution (Dittrich et al., 2009).

We demonstrated that a thin layer proton pump may work efficiently as an alkalinity sensing tool for profiling lake water. As a case study, the alkalinity level of Lake Greifen at various depths was successfully determined. These results were obtained after sampling lake water and performing the analysis at an on-shore location, thus significantly reducing the time from sampling to analysis, which is a critical factor for anoxic waters. It is conceivable that the methodology may be applied as a single-point titration system by means of a theoretical fit from the initial $\mathrm{pH}$ value, acidity constant and a single titration point, thereby drastically increasing measurement frequency. Future development will focus on the realisation of an alkalinity sensor that is deployable in situ, in analogy to a CTD probe.

\section{Acknowledgements}

The authors thank the Swiss National Science Foundation and the European Union (FP7-GA 614002-SCHeMA project) for supporting this research.

Editor: Eric H. Oelkers

\section{Additional Information}

Supplementary Information accompanies this letter at www.geochemicalperspectivesletters.org/article1709

Reprints and permission information are available online at http://www. geochemicalperspectivesletters.org/copyright-and-permissions

Cite this letter as: Ghahraman Afshar, M., Tercier-Waeber, M.-L., Wehrli, B. Bakker, E. (2017) Direct sensing of total alkalinity profile in a stratified lake. Geochem. Persp. Let. 3, 85-93.

\section{References}

Bhakthavatsalam, V., ShVareV, A., BaKKer, E. (2006) Selective coulometric release of ions from ion selective polymeric membranes for calibration-free titrations. Analyst 131, 895-900.

CRespo, G.A., GHAHRAMAN AFSHAR, M., BAKKER, E. (2012) Direct detection of acidity, alkalinity, and pH with membrane electrodes. Analytical Chemistry 84, 10165-10169.

DitTRich, M., KURZ, P., WehrLI, B. (2004) The role of autotrophic picocyanobacteria in calcite precipitation in an oligotrophic lake. Geomicrobiology Journal 21, 45-53.

DitTRICH, M., WeHrLI, B., ReICHERT, P. (2009) Lake sediments during the transient eutrophication period: Reactive-transport model and identifiability study. Ecological Modelling 220, 2751-2769.

Ghahraman Afshar, M.G., CresPo, G.A., XIE, X., BAKKeR, E. (2014) Direct alkalinity detection with ion-selective chronopotentiometry. Analytical Chemistry 86, 6461-6470.

Ghahraman Afshar, M.G., Crespo, G.A., BAKKer, E. (2015a) Thin-Layer Chemical Modula tions by a Combined Selective Proton Pump and $\mathrm{pH}$ Probe for Direct Alkalinity Detection. Angewandte Chemie 127, 8228-8231.

Ghahraman Afshar, M., Crespo, G.A., BaKKer, E. (2015b) Coulometric Calcium Pump for Thin Layer Sample Titrations. Analytical Chemistry 87, 10125-10130

Gruber, N., Wehrli, B., WÜEST, A. (2000) The role of biogeochemical cycling for the formation 24, 277-291.

KARLMARK, B JAFGR, P. FEIN, H GIEBISCH, G. (1982) Coulometric acid-base titration in nanoliter samples with glass and antimony electrodes. American Journal of Physiology-Renal Physiology 242, F95-F99.

LI, Q., WANG, F., Wang, Z.A., Yuan, D., DaI, M., Chen, J., DaI, J., Hoering, K.A. (2013) Automated spectrophotometric analyzer for rapid single-point titration of seawater total alkalinity. Environmental Science and Technology 47, 11139-11146. 
Malon, A., BAKKeR, E., Pretsch, E. (2007) Backside calibration potentiometry: Ion activity measurements with selective supported liquid membranes by calibrating from the inner side y $79,632-638$.

MÜLLER, B., WANG, Y., DitTRICH, M., WeHRLI, B. (2003) Influence of organic carbon decomposition on calcite dissolution in surficial sediments of a freshwater lake. Water Research 37, 4524-4532.

MÜLLER, B., MEYER, J.S., GÄCHTER, R. (2016) Alkalinity regulation in calcium carbonate-buffered lakes. Limnology and Oceanography 61, 341-352.

NAgY, G., FehÉR, Z., Tóth, K., Pungor, E. (1977) A novel titration technique for the analysis of streamed samples-the triangle-programmed titration technique: Part II. Argentimetric titrations. Analytica Chimica Acta 91, 97-106.

PAsche, N., Dinkel, C., Schmid, M., WehrLI, B. (2009) Physical and biogeochemical limits to internal nutrient loading of meromictic Lake Kivu. Limnology and Oceanography 54, 1863-1873,

Ramisch, F., Dittrich, M., Mattenberger, C., Wehrli, B., WÜest, A. (1999) Calcite dissolution in two deep eutrophic lakes. Geochimica et Cosmochimica Acta 63, 3349-3356.

SChrag, D.P., Higgins, J.A., MacDonald, F.A., JohnSton, D.T. (2013) Authigenic carbonate and the history of the global carbon cycle. Science 339, 540-543.

Spaulding, R.S., DeGrandpre, M.D., Beck, J.C., Hart, R.D., Peterson, B., De Carlo, E.H. DRUPP, P.S., HAMMAR, T.R. (2014) Autonomous in situ measurements of seawater alkalinity. Environmental Science and Technology 48, 9573-9581.

StumM, W., Morgan, J. (1996) Aquatic chemistry, chemical equilibra and rates in natural waters. Environmental Science and Technology Series. Third Edition, John Wiley \& Sons, Inc., New York.

VAN DER SCHOOT, B., VAN DER WAL, P., DE ROOIJ, N., WEST, S. (2005) Titration-on-a-chip, chemical sensor-actuator systems from idea to commercial product. Sensors and Actuators B: Chemical 